\title{
The icosahedral anaster
}

\author{
A slight detour?
}

\section{John P. Boyd}

Once, Samaha was flesh and blood, but now he lives only as a pattern of electrons, circulating in a tiny cube barely two centimetres on a side, plus back-ups. He had expected to sleep the long years to Sagartha, but the alarm awakened him into the virtual-reality immersion of a starship cabin.

It was an illusion, and it was the truth. He was in a starship only three metres long, hurtling between the stars. The virtual instruments would control the starship as truly as if they were real. And the planet that had triggered the alarm was real, too.

Interstellar space was filled with planets. Once, it had been thought that solar systems simply condensed in place. In reality, a young star system was a battleground of collisions and near-misses. A hundred Plutos absorbed in collisions. Another hundred flung by near-misses or triple interactions into the dark between the suns.

Iceballs, most of them, with sometimes a little rock. Why awaken him?

The AI appeared on-screen as a middleaged woman with spiky white hair. "The planet is unnatural. Perhaps a detour is necessary."

"The void is full of anasters. Worlds without stars. Why wake me?"

The screen filled with an image that reminded him of a 20-sided die he had used as a child. A light year from the nearest star, the planet should be as black as the Deep itself. But this was an infrared image, and the planet was burning up with heat.

"An icosahedron!" It was absurd. The world was half as large as Earth and almost as dense. The 12 vertices, each a vast 5 sided pyramidal mountain, should have slid back into the great depression at the centre of each triangular face. No granite, no obsidian, could hold up a mountain many hundreds of kilometres high. An icosahedron was a very bad approximation to the sphere; the vertices were nearly $30 \%$ farther from the centre than were the centres of each face.

And yet the mountains held; the rock did not flow downhill in great rivers of plastic deformation. The 20 triangles remained triangular. Disconcerted, he woke up the captain.

Ramon was not at all pleased. His virtual body sat in the co-pilot's chair, glowering. "I expected to wake up in Sagartha, dammit! I feel like a man who had already started to walk the pearly stairs to heaven and then wham! Back in the world of pain."

"Don't be so melodramatic. You have no body to feel pain. And - haven't you any curiosity?"

"Yes! Half the human race, and most of

than a million psyches. Do they want to be called back from heaven for a bit of science? Sagartha is the summation of every mystery and desire of a hundred races for half a billion years. This funny ball of rock is so insignificant ... You're watch captain. Not boss."

Samaha hung his head.

Like a lot of other humans still in carbon, he had found a pen pal among the Janx. His 'angel' was named Yth, and had tried very hard to answer all his questions. But over the very low bandwidth interstellar link, Yth had to speak in words, translated perhaps imperfectly into English, of things that could really only be explained by total immersion. And so, in time, like all the other consciousnesses crammed into the tiny hold, Samaha had chosen to flash his body into ash, and send his psyche to Sagartha.

Finally Samaha said: "Thank you, Ramon." The other waved dismissively and then was simply not there.

Samaha did not sleep. Instead, he commanded the AI to collect data during the fly-by. Were there cities on this fantastic, impossible

the rest of the galaxy, live the Life Electric in Sagartha. A whole galaxy of sophonts, bitstreams in a world free of all constraints of time and space. Immortal!" Ramon pounded the virtual desk. "I want it. I want it bad. And now ... Don't you understand, Sam? Everything is there. The religious dreams of a better world, evil-free, where a man can fly! It's all true, but it's not God's gift. It's the gift of the Janx."

That ancient race, the first to emerge as a lasting civilization, had discorporated at least a hundred million years ago, building an immense virtual-reality structure a few thousand light years from the centre of the galaxy. In time, perhaps a little lonely, they had invited other races to share. Some of the recently sentient inhabitants of the third planet around an obscure yellow star were still in carbon-and-water, back on Earth and its colonies, but most races had 'gone electric' when humans were mute banana-eaters walking on their knuckles.

"But aren't you curious? This planet is physically impossible. I want to investigate..."

"No! No! No! This ship is carrying more world? Great pentagonal towers lit only by mighty star-lamps within? Fugitives fleeing from ... what?

He would not pass near enough to see cities. At closest approach, he did learn that each face contained a large, triangular ocean, liquefied by heat bubbling up from some thoroughly artificial heat source within. He suspected that the mass was distributed non-uniformly, minimizing the strain on the impossible 5-sided mountains. He suspected or fantasized much more. But he would never know.

With paradise waiting, who would want to stay in flesh a minute longer? And yet his Christian and Muslim friends had loved the grass, and the waves slowly rolling in from the ocean, as much as he. Some passions of one's first life were precious even in the face of a promised but unimaginable paradise.

He would never know.

John Boyd has been a professor of atmospheric and oceanic science at Michigan for $\mathbf{3 0}$ years. He has published two books, 170 scientific articles and a dozen science-fiction stories. 